\title{
Article \\ Indirect Electro-Thermal Modelling of Semiconductor Diode Using Non-Linear Behavior of Volt-Ampere Characteristic
}

\author{
Michal Frivaldsky * (D) and Miroslav Pavelek
}

check for updates

Citation: Frivaldsky, M.; Pavelek, M. Indirect Electro-Thermal Modelling of Semiconductor Diode Using Non-Linear Behavior of Volt-Ampere Characteristic. Energies 2022, 15, 154. https://doi.org/10.3390/en15010154 Academic Editor: Konstantin Suslov

Received: 22 November 2021 Accepted: 20 December 2021 Published: 27 December 2021

Publisher's Note: MDPI stays neutral with regard to jurisdictional claims in published maps and institutional affiliations.

Copyright: (C) 2021 by the authors. Licensee MDPI, Basel, Switzerland. This article is an open access article distributed under the terms and conditions of the Creative Commons Attribution (CC BY) license (https:// creativecommons.org/licenses/by/ $4.0 /$ )
Department of Mechatronics and Electronics, Faculty of Electrical Engineering and Information Technologies, University of Zilina, 01026 Zilina, Slovakia; miroslav.pavelek@feit.uniza.sk

* Correspondence: michal.frivaldsky@fel.uniza.sk; Tel.: +421-51-5131604

\begin{abstract}
The aim of the proposed paper is the development of an electro-thermal model of semiconductor component using an indirect modelling approach. The approach is based on the integration of the component's electrical properties considering non-linear behavior of a V-A characteristic. In this way, the identification of semiconductor material properties considering non-linear dependencies and semiconductor volume is provided. The main aim of the presented approach is simplification of the electro-thermal interaction within finite-element modelling of the semiconductor components. In this way, it is possible to omit more complex boundary definitions and the setting of the semiconductorbased physics. The proposed methodology is presented within the development of a simulation model based on a small high-frequency rectifying diode, taking into account its geometric dimensions and the internal arrangement of its structure. Simulation was performed as a transient analysis, while the results from the steady-state operation for various operational conditions were compared to experimental measurements. Comparison between simulation and experiments is within $5 \%$ of the relative error. The achieved results represent appropriate accuracy of model behavior compared to the real operation.
\end{abstract}

Keywords: electro-thermal modeling; semiconductor; simulation; non-linear characteristic

\section{Introduction}

Thermal management currently represents a very important design issue, if the safe and stable operation of any electronic system is required. Focusing on the applications of power electronic systems, the mentioned phenomena is defined as one of the figures of merit for the evaluation of the operational characteristics. This is also due to the continuous increase in the power density of power electronic system and devices [1-4]. If semiconductor components are analyzed in more detail, it will be discovered that packing technology is improving from year to year, thus optimizing the operational performance of semiconductor devices. Currently, many types of packages are at the disposal from semiconductor manufacturers, while they represent a key ability in defining thermal properties. Thermal management is key design aspect if reliability and operational life of individual electronic components are considered. Therefore, it is recommended at the preliminary construction stage of the system that a precise analysis of the thermal performance is provided [5-9].

The ways showing how to optimize thermal management of electronic components, and thus performance of electronic systems, have been mostly based on experimental measurements. However, nowadays, more and more designers use the modelling approach utilizing modern software tools (Finite Element Method (FEM) and Computational Fluid Dynamics (CFD) analysis tools). Simulation analyses enable modification of various parameters and variables of the used materials of the analyzed system, thus reducing validation time, thus eliminating the need for experiments. Simultaneously, the simulation software is useful if safe operation conditions and reliability are analyzed [5,6]. The simulation of thermal performance reduces the potential risks of overheating and enables the development of products with more stable functionality under high environmental temperature 
fluctuations. It also eliminates the need for the development of physical prototypes until the final design stage of an electronic component has been reached before mass production. For these facts, it is important that we are informed about the component material properties, because only with proper information is it possible to achieve validated results compared to experimental verification [10-14].

Currently, there are several experimental instrumentations that are able to precisely identify the thermal behavior of electronic systems. One of the most used and suitable is infrared thermography. However, to receive accurate results related to the thermal behavior of the component during measurements, it is very important to provide experiments within a controlled environment. Based on this fact, it is important to maintain constant operational parameters, such as ambient temperature, air humidity, airflow rate, etc. This puts high demands on laboratory equipment and hardware disposal. For this reason, the exact and reconfigurable simulation model of electronic components represents an advantageous and comfortable way for identification of its thermal performance even before the pre-design stage of the whole system. This approach enables the elimination of any undesirable behavior during research and development. The Printed Circuit Board (PCB) design is another factor influencing the thermal performance of the system. It provides the possibility of dissipating the heat generated in the electronic components. Therefore, if a single component is under consideration, it is important to define the side effects of other subsystems that influence the component operation [15-19].

Considering semiconductor components, it is known that they represent devices with non-linear characteristics. Their shape is formed dependent on the operational conditions, while variations in the values of electrical and thermal conductivities are the main parameters affecting the electro-thermal behavior of semiconductors. Therefore, if the exact electro-thermal model of a semiconductor component is under consideration, the non-linear behavior of variables must be addressed by the model to obtain accurate results for wide operational conditions [20-23].

The paper deals with the procedure of electro-thermal modelling of the semiconductor diode using COMSOL software. The developed model is characterized by multi-physics behavior, i.e., the electrical domain and thermal domain are evaluated during simulations. An electrical domain defines operational conditions relevant for the electric circuit in which the diode is being operated. Then, based on definitions, the variables responsible for thermal field distribution are identified using results from an electrical domain. The main feature of the presented modeling approach is that it considers real non-linear behavior of V-A characteristic, while the values of required variables (conductivities) are indirectly extracted from V-A dependencies, while also considering temperature influence. The proposed methodology and simulation model design is supported here by the description of subdomains settings. It means that geometrical, material, and structural properties of individual component's parts are given. At the end of the paper, the evaluation of simulation model performance is obtained by way of comparisons to experimental measurements.

\section{Non-Linear VA Characteristic Simulation}

The Simulation model is created in the form of equivalence with complex models using boundary conditions defined by semiconductor physics. This approach is based on the simple electrical interface, where the semiconductor part (in this case diode) is described by conductivity function for an electrical interface, and by thermal parameters of pure silicon material. This approach can be also easily used for simulation of multiple parts within the PCB and, thus, for the overall thermal performance of the electronic system.

The proposed approach (Figure 1) is composed of the following steps: 


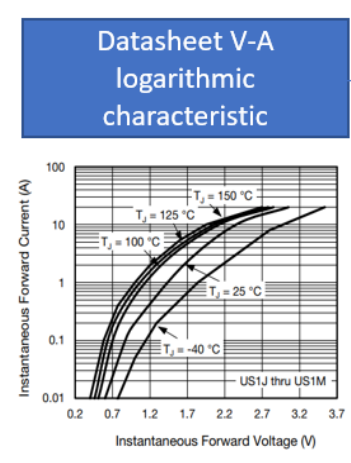

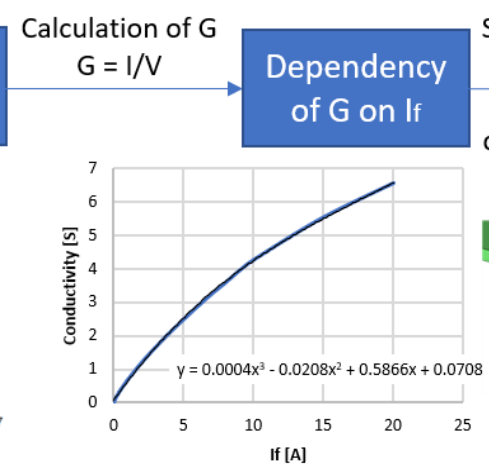

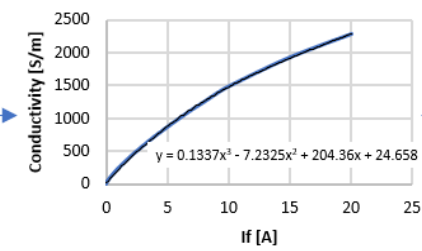
conductivity = 1

$$
\mathrm{s} / \mathrm{m}
$$
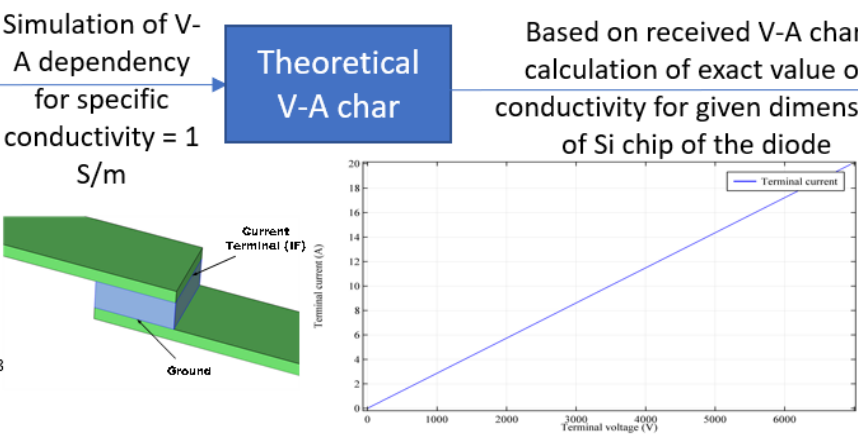

Implementation of char. Into COMSOL for having exact dependency of $\mathrm{V}$ A char. compared to datasheet
Based on received V-A char. calculation of exact value of conductivity for given dimension of Si chip of the diode

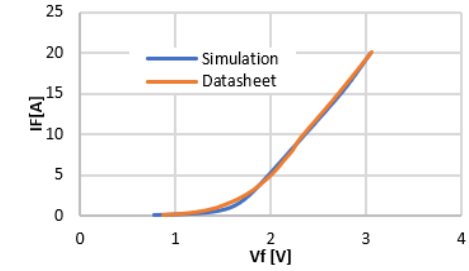

Figure 1. Simplified block diagram of the proposed approach ( $\varepsilon$ is electrical permittivity).

1. In the first step, it is important to have VA characteristics (Figure 2a) of specific semiconductor diode (considering thermal dependency). It can be easily extracted from the datasheet of given part. The obtained VA characteristics are then refined to conductivity characteristics (1) that can be seen in Figure $2 \mathrm{~b}$.

$$
\mathrm{I}_{\mathrm{i}}\left(\mathrm{T}_{\mathrm{i}}, \mathrm{V}\right) \rightarrow \mathrm{G}_{\mathrm{i}}\left(\mathrm{T}_{\mathrm{i}} ; \mathrm{I}\right)=\frac{\mathrm{I}\left(\mathrm{T}_{\mathrm{i}}, \mathrm{V}\right)}{\mathrm{V}}
$$

where $I_{i}$ is $i$-th sample of the value of current, $T_{i}$ is the $i$-th sample of temperature, $G_{i}$ is the $\mathrm{i}$-th sample of the value of conductivity and $\mathrm{V}$ is voltage.

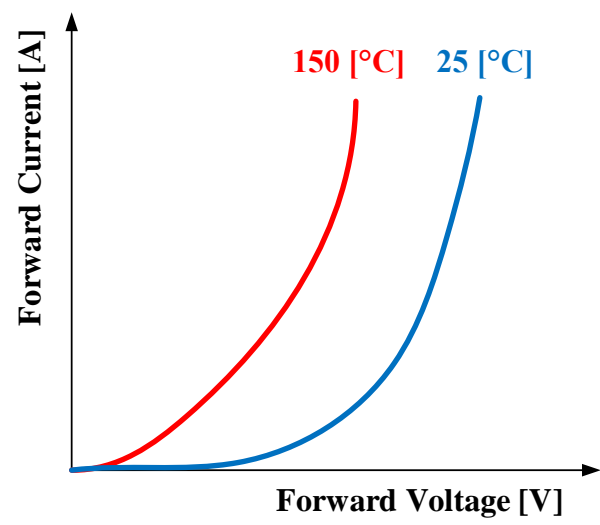

(a)

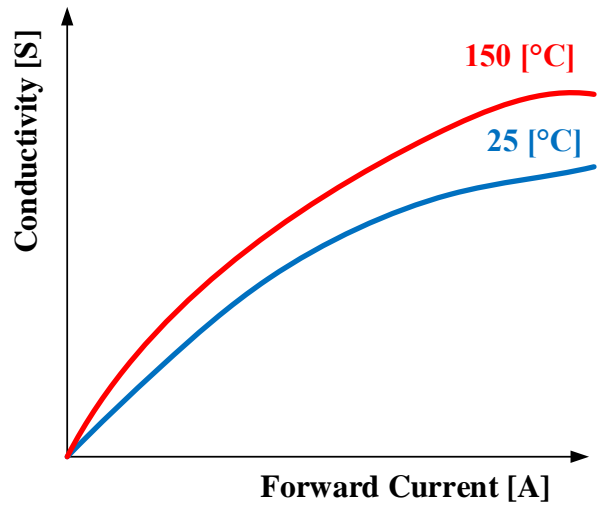

(b)

Figure 2. (a) VA characteristic; (b) conductivity characteristics.

2. The next step is the determination of the thermal coefficient of the given semiconductor diode based on the conductivity characteristics from the first step (Figure 2b). The thermal coefficient can be determined based on the temperatures limits for a given application (semiconductor part) using Equation (2). The thermally adjusted conductivity is then given be (3). In order to reach higher accuracy, the temperature coefficient can by determined for more temperature intervals independently. Within 
the final result more dependencies are available, which can be added to the simulation model for each temperature interval.

$$
\begin{gathered}
\mathrm{k}_{\mathrm{T}}(\mathrm{I})\left[\frac{\mathrm{S}}{{ }^{\circ} \mathrm{C}}\right]=\frac{\mathrm{G}_{2}\left(\mathrm{~T}_{2} ; \mathrm{I}_{2}\right)[\mathrm{S}]-\mathrm{G}_{1}\left(\mathrm{~T}_{1} ; \mathrm{I}_{1}\right)[\mathrm{S}]}{\mathrm{T}_{2}\left[{ }^{\circ} \mathrm{C}\right]-\mathrm{T}_{1}\left[{ }^{\circ} \mathrm{C}\right]} \\
\mathrm{G}\left(\mathrm{T}_{\text {real }} ; \mathrm{I}\right)[\mathrm{S}]=\frac{\mathrm{I}_{25^{\circ} \mathrm{C}}[\mathrm{A}]}{\mathrm{V}[\mathrm{V}]}+\mathrm{k}_{\mathrm{T}}(\mathrm{I})\left[\frac{\mathrm{S}}{{ }^{\circ} \mathrm{C}}\right] *\left(\mathrm{~T}_{\text {real }}\left[{ }^{\circ} \mathrm{C}\right]-25\left[{ }^{\circ} \mathrm{C}\right]\right)
\end{gathered}
$$

where $\mathrm{k}_{\mathrm{T}}$ is the thermal coefficient, $\mathrm{G}_{2}$ is the higher value of diode conductivity for given temperature, $T_{2}$ is the higher temperature from chosen temperature interval, $I_{2}$ is higher current from chosen temperature interval, $G_{1}$ is the lower value of diode conductivity for a given temperature, $\mathrm{T}_{1}$ is the lower temperature from chosen temperature interval, $I_{1}$ is lower current from chosen temperature interval, and $T_{\text {real }}$ is the actual temperature of the material.

3. Within the third step, the mechanical dimensions of the package, pads, and ideally also DIE size and bonding diagram, are identified. Receiving the information on DIE size and bonding diagram can be complicated because mostly this is confidential information. Otherwise, it is possible to estimate it from a similar part. The second approach is to consider it as a main part of the heat that is transferred through the contacts of the part (these are in most cases described within the datasheet) (Figure 3).

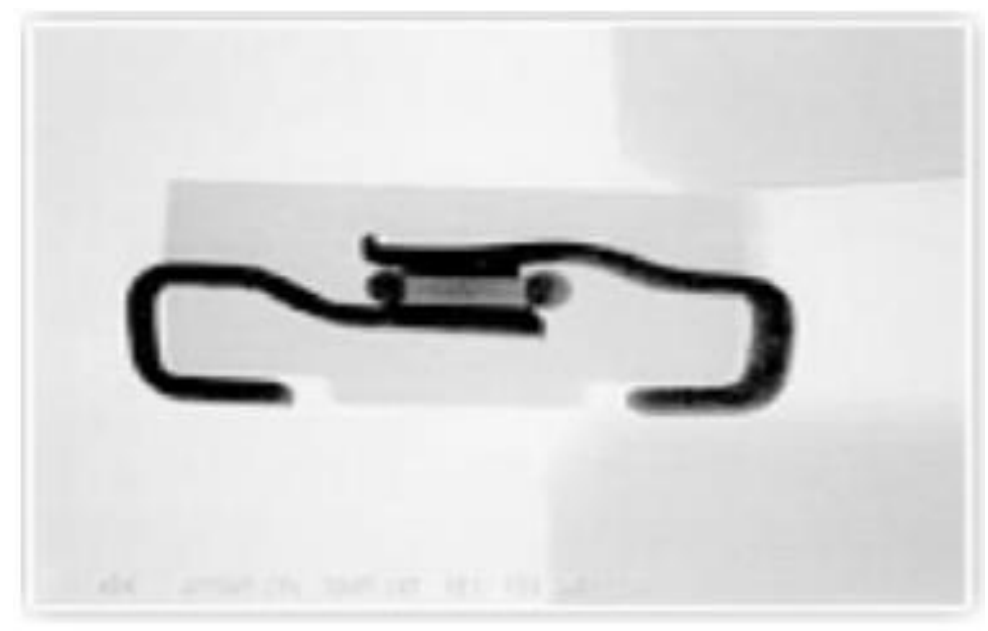

Figure 3. X-ray of semiconductor diode in SMA Package for the DIE size estimation.

4. The design of the simulation model (electrical domain) considers given geometrical parameters, which are used to determine the specific conductivity of the electrical path composed of contacts, bonding, and DIE itself. In this step, the specific conductivity is determined for the DIE conductivity equal to " $\sigma_{S}=1[\mathrm{~S} / \mathrm{m}]$ " (material settings) (Figure 4) The Forward Current in the initial simulation is set to " $\mathrm{I}_{\mathrm{F}(\mathrm{AV})}=1[\mathrm{~A}]$ ".

5. The conductivity coefficient can be simply determined using Equation (4). During this step the VA characteristic for this simulation has linear shape, because the value of the conductivity is constant (Figure $5 b$ ).

$$
\mathrm{G}_{\mathrm{S}}[\mathrm{S}]=\frac{\mathrm{I}[\mathrm{A}]}{\mathrm{U}[\mathrm{V}]} \rightarrow \mathrm{g}_{\text {coeff }}[1 / \mathrm{m}]=\frac{\sigma_{\mathrm{S}}[\mathrm{S} / \mathrm{m}]}{\mathrm{G}_{\mathrm{S}}[\mathrm{S}]}=\frac{1[\mathrm{~S} / \mathrm{m}]}{\mathrm{G}_{\mathrm{S}}[\mathrm{S}]}
$$

where $G_{S}$ is the conductivity of the diode, $g_{\text {coeff }}$ is zhe conductivity coefficient, $\mathrm{I}_{\mathrm{F}}$-is a material specific conductivity. 


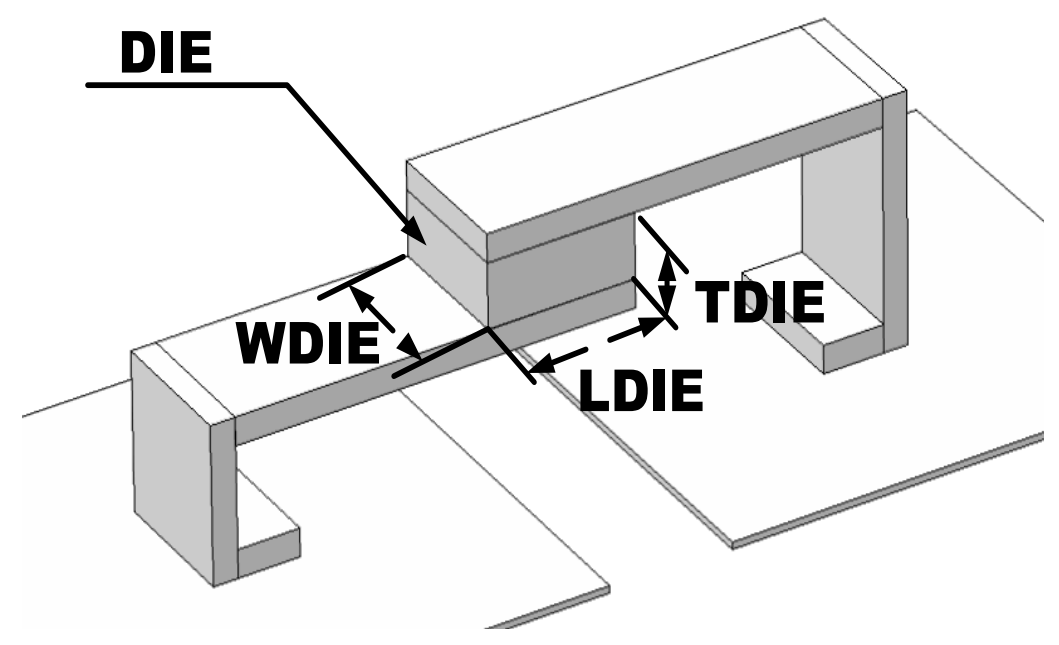

Figure 4. Initial Model Geometry.

6. The thermally adjusted conductivity characteristic, obtained in the second step needs to be multiplied by the conductivity coefficient (5) found in the fifth step.

$$
\sigma_{\text {new }}\left(\mathrm{T}_{\text {real }} ; \mathrm{I}\right)[\mathrm{S} / \mathrm{m}]=\mathrm{G}\left(\mathrm{T}_{\text {real }} ; \mathrm{I}\right)[\mathrm{S}] * \mathrm{~g}_{\text {coeff }}[1 / \mathrm{m}]
$$

where $\sigma_{\text {new }}$ is the new specific conductivity of the diode material, $\mathrm{T}_{\text {real }}$ is the actual temperature of the diode.

7. The last step is the design of the simulation model composed of both electrical and thermal interface, while using the obtained conductivity function for DIE material settings (this step is described more in detail within Sections 3 and 4).

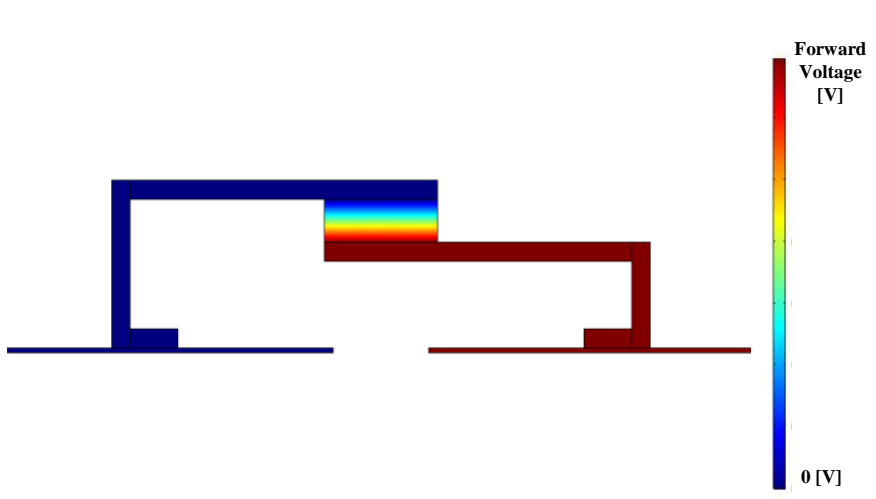

(a)

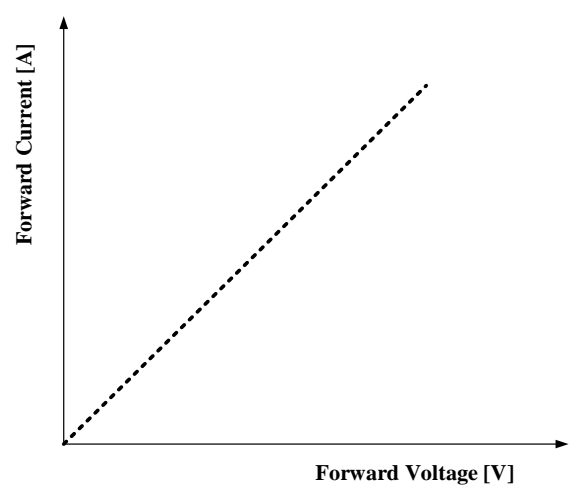

(b)

Figure 5. Example of simulation result: (a) Forward Voltage for specific current; (b) Forward Current dependency on Forward Voltage.

Thanks to the previously described approach, the thermal behavior of the system, considering variations of the value of current, can be determined without the necessity of the use of complex semiconductor physic settings. The presented modelling approach can also be used for modelling of the reverse part of VA characteristic, while the final material settings need to be divided in to two intervals (Maximal reverse Current) $\mathrm{I}_{\mathrm{RM}}$ to 0 and 0 to (Maximal Forward Current) $\mathrm{I}_{\mathrm{FM}}$.

\section{Generalized Simulation Model of Selected Semiconductor Diode}

The generalized model with material settings based on Section 2 can be made in various simulation environments like ANSYS or COMSOL Multiphysics, etc. For verification 
purposes, we have selected the COMSOL environment. The generalized 3D model of semiconductor diode is based on the predefined Multiphysics interface "Joule Heating". Joule heating interface is composed of "Electrical currents" (EC) physic and "Heat transfer in solid" (HTS) physic. This modelling approach is used instead of "Semiconductor interface" because of its lower demands on computation power. The simulation itself is defined within the time domain; thus, the results can be easily compared and verified with experimental measurements. If only steady-state analysis was considered then the computational time would be reduced, so it would be possible to determine operational characteristics of the device more flexibly.

As was mentioned above, the JH interface contains the EC domain, which uses a predefined set of Equations (6)-(9) to compute power losses within the structure.

$$
\begin{gathered}
\nabla * \mathrm{~J}=\mathrm{Q}_{\mathrm{j}} \\
\mathrm{J}=\sigma \mathrm{E}+\frac{\partial \mathrm{D}}{\partial \mathrm{t}}+\mathrm{J}_{\mathrm{e}} \\
\mathrm{E}=-\nabla \mathrm{V} \\
\mathrm{Q}_{\mathrm{e}}=\mathrm{J} * \mathrm{E}
\end{gathered}
$$

where " $\mathrm{J}$ " is the current density, " $\mathrm{Q}_{\mathrm{j}}$ " is the current source, " $\sigma$ " is the linearized resistivity, " $\mathrm{E}$ " is the vector of the electric field, " $\mathrm{D}$ " is the vector of electric field displacement, " $\mathrm{V}$ " is the electric potential, and " $\mathrm{Q}_{\mathrm{e}}$ " is the value of joule loses in given calculation step.

The JH interface then uses the computed power losses from the EC physic as input values for HTS to calculate the temperature based on the predefined Equations (10) and (11).

$$
\begin{gathered}
\rho \mathrm{C}_{\mathrm{P}} \frac{\partial \mathrm{T}}{\partial \mathrm{t}}+\rho \mathrm{C}_{\mathrm{P}} \mathrm{u} * \nabla \mathrm{T}+\nabla * \mathrm{q}=\mathrm{Q}_{\mathrm{e}}+\mathrm{Q}_{\text {ted }} \\
\mathrm{q}=-\mathrm{k} \nabla \mathrm{T}
\end{gathered}
$$

where " $\rho$ " is the material density, " $\mathrm{C}_{\mathrm{P}}$ " is the specific heat capacity, " $\mathrm{T}$ " is the temperature, " $q$ " is the heat flux, " $u$ " is the velocity vector, " $\mathrm{Q}_{\mathrm{e}}$ " is the external heat source, "Qted" is the thermoelastic damping, and " $\mathrm{k}$ " is the thermal conductivity.

In this case, the simplified equation for the electromagnetic heat source is used, which can be seen below:

$$
\rho C_{\mathrm{P}} \frac{\partial \mathrm{T}}{\partial \mathrm{t}}-\nabla *(\mathrm{k} \nabla \mathrm{T})=\mathrm{Q}_{\mathrm{e}}
$$

The Joule Heating interface also uses the output temperature from the HTS as an input in the next calculation step of EC, so the thermal characteristics of the material are respected.

The proposed model can be divided into three main domains, which are:

- Environment (in this case Air);

- Contacts (PCB Pads + Package Contacts + Bonding, generally used high electri$\mathrm{cal} /$ thermal conductivity materials);

- DIE (Silicon chip).

The simulation model domains are easily reconfigurable by geometrical parameters that can be seen in Figure 6. However, for every type of package, a new geometry with parameters that are best suited for its description needs to be designed. With a wide library portfolio of reconfigurable models, it is then possible to simulate the whole electronic system or PCBs thermal performance more flexibly. 


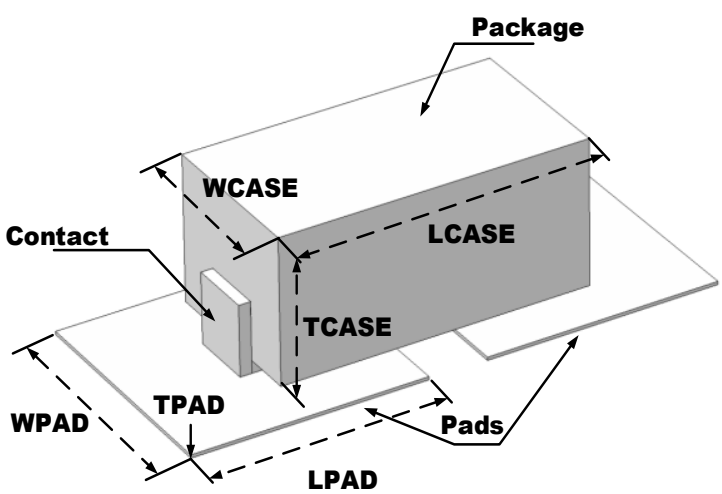

(a)

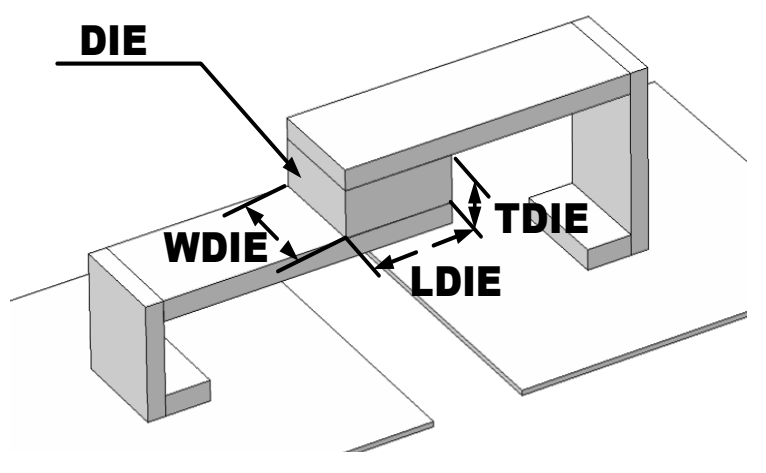

(b)

Figure 6. Generalized Model of Semiconductor Diode in SMD Package (a) Package/PADS; (b) DIE.

Next part of simulation model design is definitions on the boundary settings, which are described in Table 1.

Table 1. General Boundary Settings.

\begin{tabular}{ccccc}
\hline \multicolumn{5}{c}{ Domain Settings for Electrical Currents Physic } \\
\hline Domain & $\begin{array}{c}\text { Current } \\
\text { Conservation }\end{array}$ & $\begin{array}{c}\text { Electrical } \\
\text { Insulation }\end{array}$ & $\begin{array}{c}\text { Initial Electric } \\
\text { Potential }\end{array}$ & $\begin{array}{c}\text { Applicable } \\
\text { Equations }\end{array}$ \\
\hline DIE & Yes & No & 0 & $5,6,7$ \\
Package & Yes & Yes & 0 & $5,6,7$ \\
Contacts & Yes & No & 0 & $5,6,7$ \\
Pads & Yes & No & 0 & $5,6,7$ \\
Environment & Yes & Yes & 0 & $5,6,7$ \\
\hline & Domain Settings for Heat Transfer in Solid Physic & \\
\hline Domain & Solid & Initial & Outflow & Applicable \\
& & Values & Heat Flux & Equations \\
\hline DIE & Yes & $25\left({ }^{\circ} \mathrm{C}\right)$ & No & 10,11 \\
Package & Yes & $25\left({ }^{\circ} \mathrm{C}\right)$ & No & 10,11 \\
Contacts & Yes & $25\left({ }^{\circ} \mathrm{C}\right)$ & No & 10,11 \\
Pads & Yes & $25\left({ }^{\circ} \mathrm{C}\right)$ & No & 10,11 \\
Environment & Yes & $25\left({ }^{\circ} \mathrm{C}\right)$ & Yes & 10,11 \\
\hline
\end{tabular}

The material parameters can be set through the material interface, where it is important to correctly define the values of the Electrical Conductivity and the Relative Permittivity for all of the domains within the Electric Current interface. For the Heat-Transfer simulation the Heat Capacity, Density, and Thermal Conductivity are required variables. The values of the individual parameters of the most used materials can be seen in Tables 2 and 3 as well.

Table 2. General Material Settings (Electrical Interface).

\begin{tabular}{ccc}
\hline & Material Parameters (Electrical Interface) \\
\hline Domain & $\begin{array}{c}\text { Electrical } \\
\text { Conductivity (S/m) }\end{array}$ & $\begin{array}{c}\text { Relative } \\
\text { Permittivity (-) }\end{array}$ \\
\hline DIE (Silicon) & $\sigma(\mathrm{T}$, IF)-(Equation (13)) & 11.7 \\
Package (Epoxy) & 0 & 3.6 \\
Contacts (Copper) & $5.9987 \times 10^{7}$ & 1 \\
Pads (Copper) & $5.998 \times 10^{7}$ & 1 \\
Environment (Air) & 0 & 1 \\
\hline
\end{tabular}


Table 3. General Material Settings (Thermal Interface).

\begin{tabular}{cccc}
\hline \multicolumn{4}{c}{ Material Parameters (Thermal Interface) } \\
\hline Domain & Heat Capacity $\left(\mathbf{J} /\left(\mathbf{k g}{ }^{\circ} \mathbf{C}\right)\right)$ & $\begin{array}{c}\text { Density } \\
\left(\mathbf{k g} / \mathbf{m}^{\mathbf{3}}\right)\end{array}$ & $\begin{array}{c}\text { Thermal Conductivity } \\
\left(\mathbf{W} /\left(\mathbf{m}{ }^{\circ} \mathbf{C}\right)\right)\end{array}$ \\
\hline DIE (Silicon) & 700 & 2329 & 130 \\
Package (Epoxy) & 1000 & 1250 & 0.35 \\
Contacts (Copper) & 385 & 8960 & 400 \\
Pads (Copper) & 385 & 8960 & 400 \\
Environment (Air) & 1000 & 1.839 & 0.026 \\
\hline
\end{tabular}

Equation (13) represents the general form of dependency of specific conductivity written as a fourth order approximation. This approximation can be obtained using various software (MATLAB or directly in EXCEL, etc.). Considering the shape of the characteristic, it is sufficient to use mentioned 4-th order approximation of the dependency of specific conductivity.

$$
\sigma_{\text {new }}\left(T_{\text {real }} ; I\right)=\left(\left(\sum_{n=1}^{5} a_{n} * I_{F}^{5-n}\right)+k_{T} *\left(T_{\text {real }}-25\right)\right) * g_{\text {coeff }}
$$

\section{Customized Simulation Model of Semiconductor Diode}

The customization process of the proposed model to the specified power diode is performed by the change in the geometrical parameters of the reconfigurable model. Thus, a new geometry for different package options, like modification of the conductivity function, is obtained (see step-by-step approach in Section 2).

For the verification of the proposed procedure, we used the power diode "US1MHE3". The basic materials used in these models are mostly the same. Therefore, it is possible to use general material settings from Table 2, with a specific function for the electrical conductivity of the DIE.

1. From V-A Characteristics to Conductivity characteristics of selected diode.

The extracted VA characteristic from the datasheet of US1MHE3 [24] can be seen in Figure $7 \mathrm{a}$, while temperature dependency for $25\left({ }^{\circ} \mathrm{C}\right), 100\left({ }^{\circ} \mathrm{C}\right)$, and $150\left({ }^{\circ} \mathrm{C}\right)$ is considered. The Figure $7 \mathrm{~b}$ corresponds with the temperature dependency of the conductance characteristics of the given diode. The fourth order approximation of conductivity dependency on forward current corresponds to Equation (14).

$$
\mathrm{G}_{25^{\circ} \mathrm{C}}\left(25^{\circ} \mathrm{C}, \mathrm{I}_{\mathrm{F}}\right)=-0.045 \mathrm{I}_{\mathrm{F}}^{4}+0.25 \mathrm{I}_{\mathrm{F}}^{3}-0.51 \mathrm{I}_{\mathrm{F}}^{2}+1 \mathrm{I}_{\mathrm{F}}+0.014 \mathrm{e}^{-2}
$$

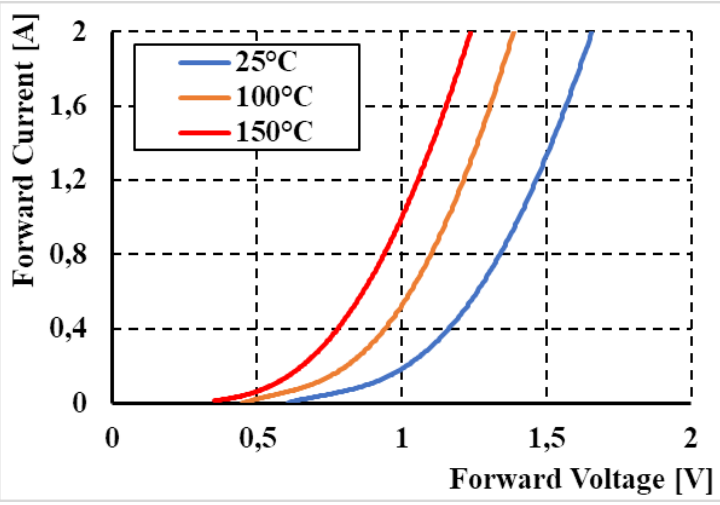

(a)

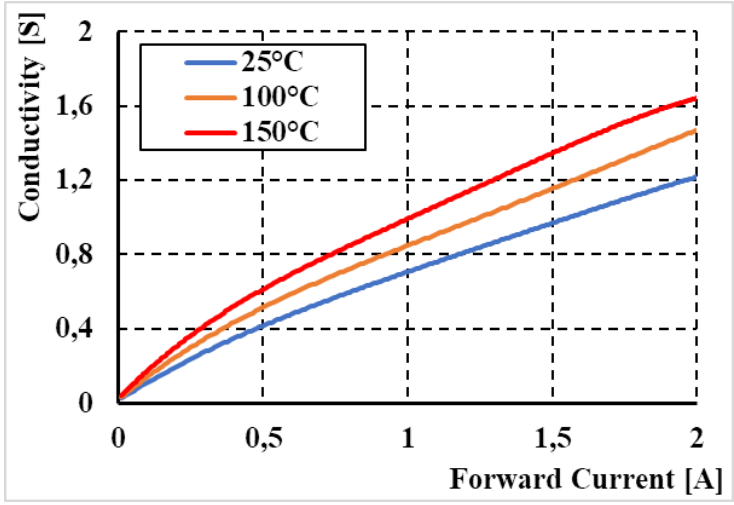

(b)

Figure 7. (a) V-A Characteristic of US1MHE3 diode; (b) Conductance Characteristic of US1MHE3 diode. 
2. Thermal Coefficient Determination.

The thermal coefficient is determined for temperature interval from $25\left({ }^{\circ} \mathrm{C}\right)$ to $150\left({ }^{\circ} \mathrm{C}\right)$ and its dependency can be seen in Figure 8. The fourth order approximation of thermal coefficient " $k_{T}$ " in dependency on forward current corresponds to Equation (15).

$$
k_{T}\left(I_{F}\right)=-8 e^{-8} I_{F}^{4}+4 e^{-6} I_{F}^{3}-1 e^{-4} I_{F}^{2}+1.4 e^{-3} I_{F}+5 e^{-4}
$$

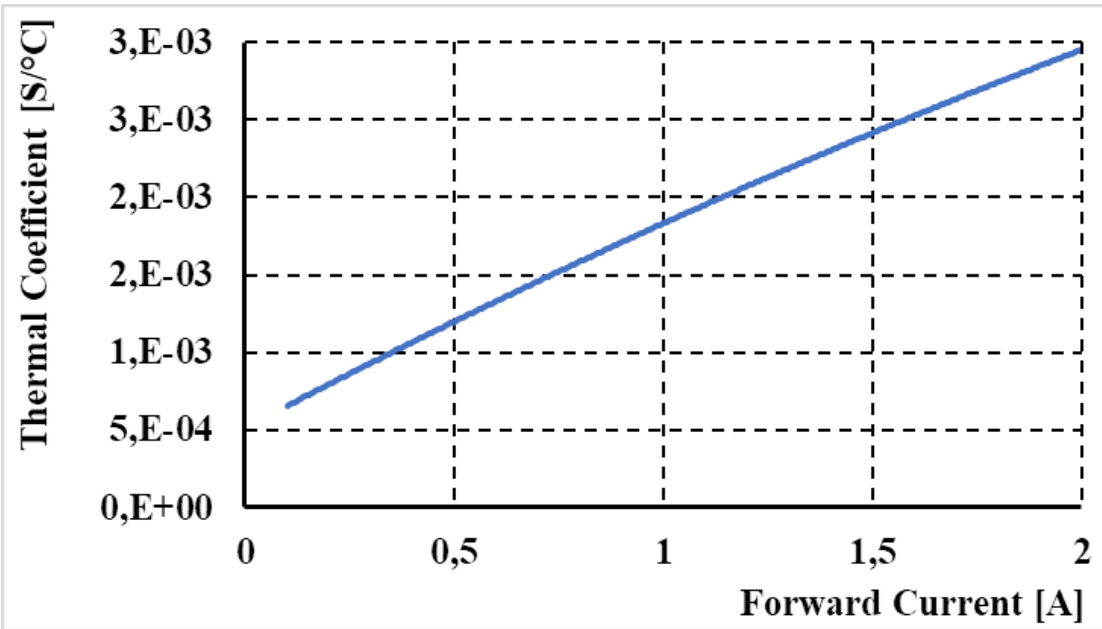

Figure 8. Thermal coefficient dependency on the diode forward current.

3. Package Dimensions + DIE and Bonding size estimation.

The diode's package dimensions are listed in the datasheet (Figure 9). The DIE dimensions are estimated based on the similar device in the same package (Figure 3).
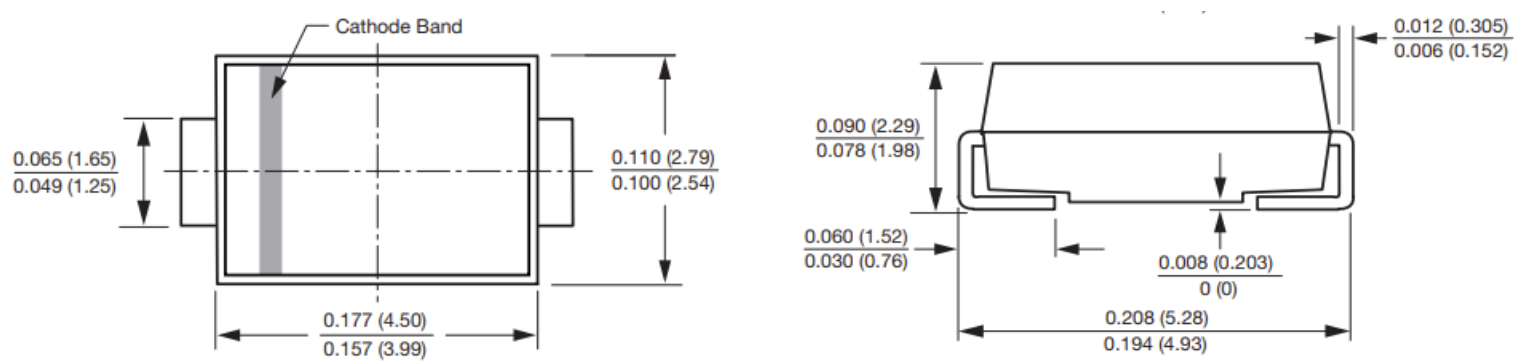

Figure 9. US1MHE3 Package dimensions from datasheet.

The geometrical parameters of the package (SMA) and estimated geometrical parameters of the DIE that are used in the simulation model can be seen in Table 4.

Table 4. Geometrical Parameters of "US1MHE3".

\begin{tabular}{cccc}
\hline Domain & Width $(\mathbf{m})$ & Length $(\mathbf{m})$ & Thickness $(\mathbf{m})$ \\
\hline DIE & $1.10 \times 10^{-3}$ & $1.20 \times 10^{-3}$ & $0.46 \times 10^{-3}$ \\
Package & $2.79 \times 10^{-3}$ & $5.28 \times 10^{-3}$ & $2.29 \times 10^{-3}$ \\
Pads & $1.2 \times 10^{-3}$ & $1 \times 10^{-3}$ & $50 \times 10^{-6}$ \\
Environment & $10 \times 10^{-3}$ & $10 \times 10^{-3}$ & $5 \times 10^{-3}$ \\
\hline
\end{tabular}

4. Preliminary Simulation Model and Conductivity Coefficient determination. 
The results from the preliminary simulation model using settings described in previous sections can be seen in Figure 10. From these results, it is possible to determine the conductivity coefficient as in (16) and (17).

$$
\begin{gathered}
\mathrm{G}_{\mathrm{S}}[\mathrm{S}]=\frac{\mathrm{I}[\mathrm{A}]}{\mathrm{U}[\mathrm{V}]}=2.87 \mathrm{e}^{-3}[\mathrm{~S}] \\
\mathrm{g}_{\text {coeff }}[1 / \mathrm{m}]=\frac{\sigma_{\mathrm{S}}[\mathrm{S} / \mathrm{m}]}{\mathrm{G}_{\mathrm{S}}[\mathrm{S}]}=\frac{1[\mathrm{~S} / \mathrm{m}]}{2.87 \mathrm{e}^{-3}[\mathrm{~S}]}=348.432[1 / \mathrm{m}]
\end{gathered}
$$

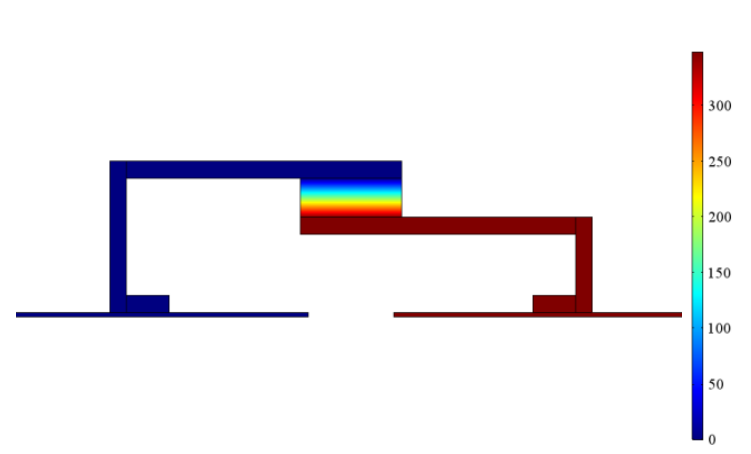

(a)

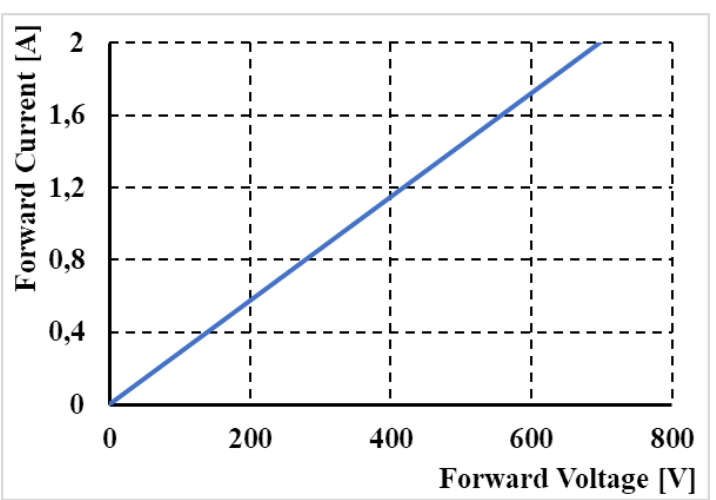

(b)

Figure 10. Customized Model Result: (a) Forward Voltage for specific current; (b) Forward Current dependency on Forward Voltage.

5. New conductivity characteristic and simulation model comparison.

The received conductivity characteristic using the previously described procedures defined by Equation (18):

$$
\begin{aligned}
\sigma_{\text {new }}\left(\mathrm{T}_{\text {real }} ; \mathrm{I}_{\mathrm{F}}\right)= & {\left[-0.045 \mathrm{I}_{\mathrm{F}}^{4}+0.25 \mathrm{I}_{\mathrm{F}}^{3}-0.51 \mathrm{I}_{\mathrm{F}}^{2}+1 \mathrm{I}_{\mathrm{F}}+0.014 \mathrm{e}^{-2}\right.} \\
& +\left(-8 \mathrm{e}^{-8} \mathrm{I}_{\mathrm{F}}^{4}+4 \mathrm{e}^{-6} \mathrm{I}_{\mathrm{F}}^{3}-1 \mathrm{e}^{-4} \mathrm{I}_{\mathrm{F}}^{2}+1.4 \mathrm{e}^{-3} \mathrm{I}_{\mathrm{F}}+5 \mathrm{e}^{-4}\right) \\
& \left.*\left(\mathrm{~T}_{\text {real }}-25\right)\right] * 348.432
\end{aligned}
$$

The accuracy of this approach is evaluated by comparison of the simulated voltampere characteristic (VA) characteristics with VA characteristics given by the datasheet, while temperature dependency is considered as well (Figure 11). For a given range of diode forward current, we can say that from an electrical point of view, the relative error of the proposed model is less than $1 \%$ for $25{ }^{\circ} \mathrm{C}$ characteristic, less than $2 \%$ for $100{ }^{\circ} \mathrm{C}$ characteristic, and less than $5 \%$ for $150{ }^{\circ} \mathrm{C}$ characteristic.

Main difference is recorded for high operational temperature, i.e., 150 degrees. This level of the operational temperature represents limiting value of the Si semiconductor technology, while electro-thermal process and non-linear dependencies are potentially much higher compared to lower temperatures. Therefore, the highest difference is achieved for potentially the highest allowed operational temperature. 


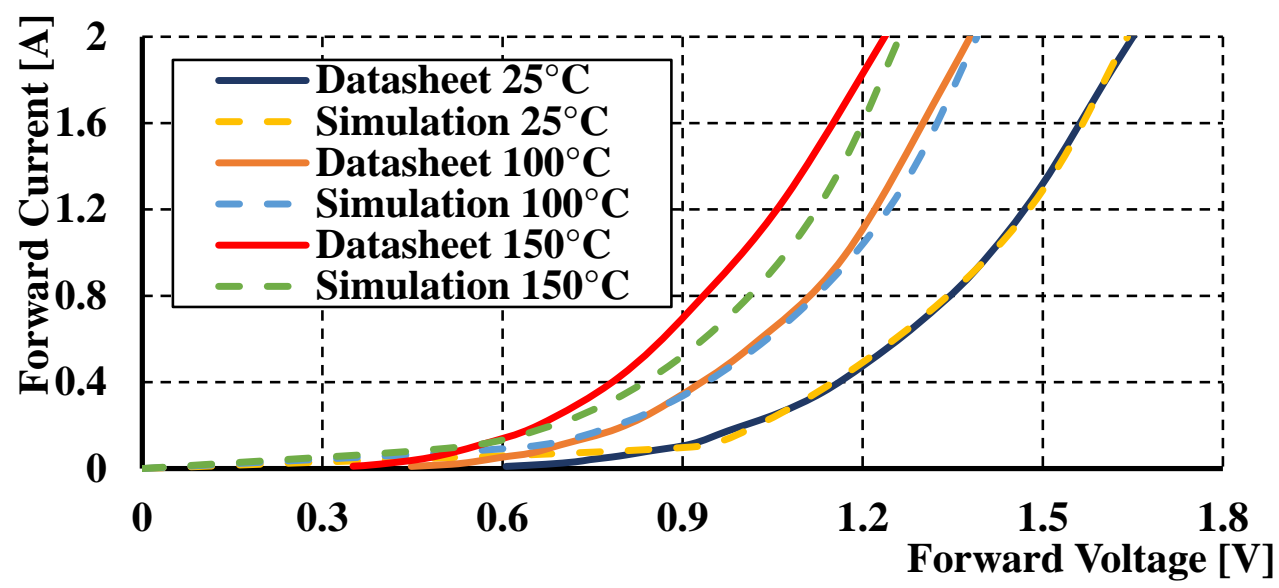

Figure 11. Simulated VA characteristics (dotted line) compared to VA characteristics from datasheet (full line).

\section{Comparisons of Simulation Results with Experimental Measurements}

The proposed simulation model is verified for different current values (during steady state operation), while received results were compared with the results from experimental measurement (Figure 12).
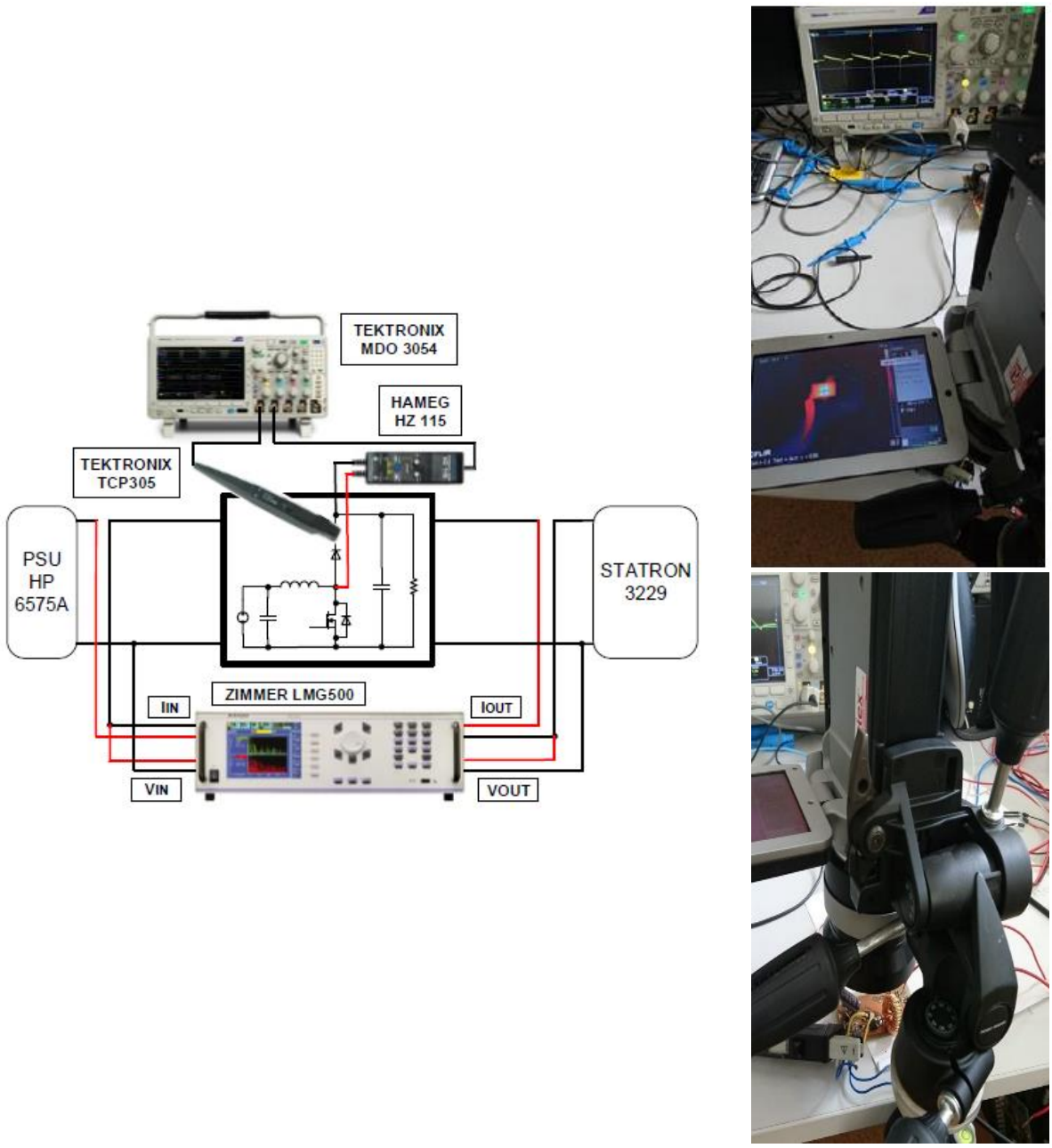

(a)

(b)

Figure 12. Measurement Situation: (a) block diagram; (b) photo from experimental measurements. 
The investigation of operation within experiments was performed by way of implementation of the selected diode, within the main circuit of DC-DC converter (boost type). The three different diode currents were set having the same RMS values as within simulation). Thermal behavior of the diode was evaluated with the use of the FLIR SC600 thermal camera. The input/output parameters of the converter circuit are listed in Table 5.

Table 5. Operational Parameters of the Boost Converter during the Tests.

\begin{tabular}{cc}
\hline Parameter & Value \\
\hline Input converter voltage $(\mathrm{V})$ & 12 \\
Output converter voltage $(\mathrm{V})$ & 24 \\
Input converter current $(\mathrm{A})$ & $0.31,0.42,0.53$ \\
Output converter current $(\mathrm{A})$ & $0.15,0.2,0.25$ \\
Converter switching frequency $(\mathrm{kHz})$ & 100 \\
\hline
\end{tabular}

The experimental setup is shown in Figure 12. The diode voltage and current were measured by the current and voltage probe while time-waveforms were visualized on the digital oscilloscope. The input and output voltages and currents were measured with a precise power analyzer, while the individual settings reflected simulation conditions.

The experiments were made based on the experimental set-up described above. The focus was given on infrared thermo-vision measurements of the selected power diode. Figure 13a shows the temperature distribution within the surface of the investigated component indicating a hot spot during the experimental measurement. This point is located in the space where a silicon power chip is integrated within the diode package. As can be seen, the maximum temperature for the situation of $\mathrm{I}_{\mathrm{F}(\mathrm{RMS})}=300 \mathrm{~mA}$ has reached approximately $120^{\circ} \mathrm{C}$.

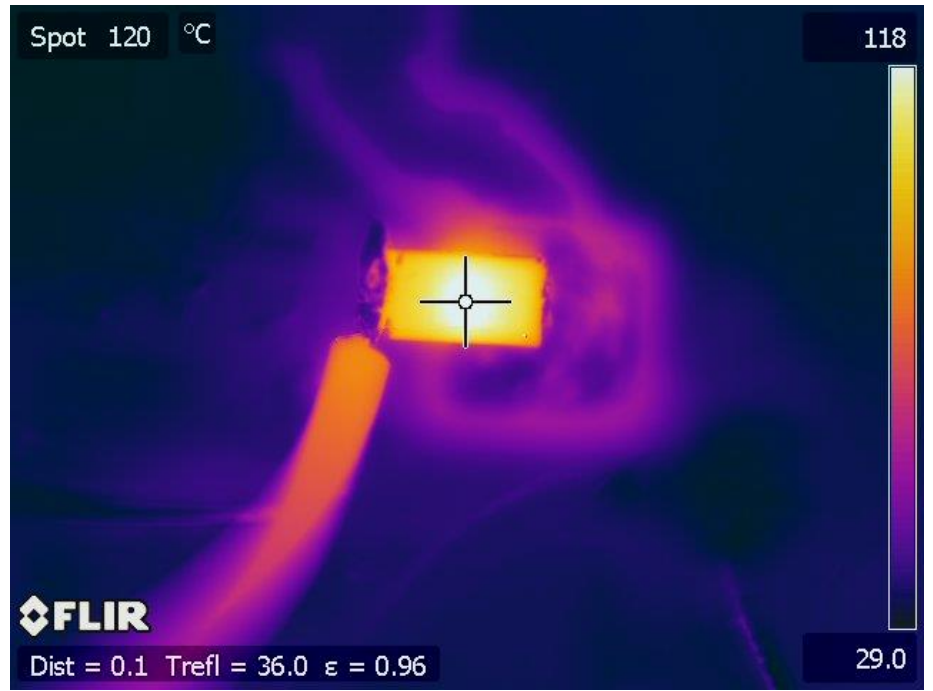

(a)

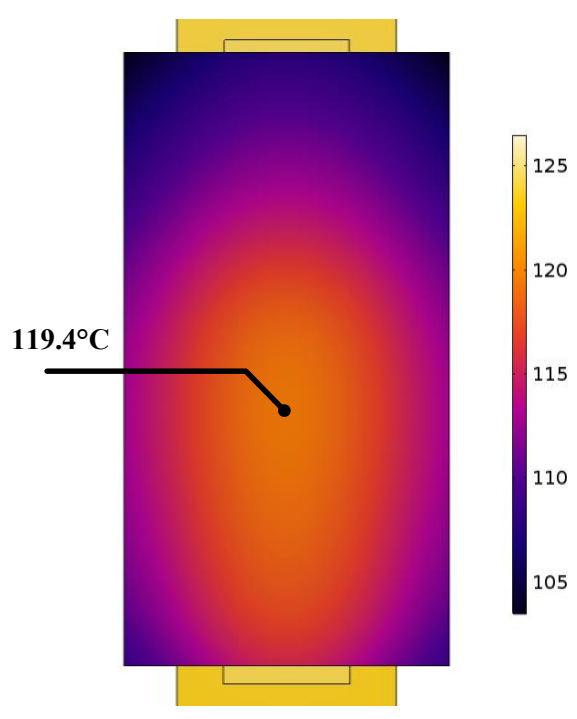

(b)

Figure 13. The Comparison for 300 (mA) forward current: (a) measurement; (b) simulation result.

Simultaneously, to verify the electro-thermal behavior of the simulation model, Figure $13 \mathrm{~b}$ shows the result of the simulation analysis. The evaluation of the temperature at the hot spot of the component shows that the maximum reached during simulation is $119.4{ }^{\circ} \mathrm{C}$. This value is very close to the result, which was reached during measurement, and it is seen that temperature distribution is similar comparing both results. The relative error for this value of current represents $-0.5 \%$.

Measurement valid for the second value of the diode's current is shown in Figure 14, while $\mathrm{I}_{\mathrm{F}(\mathrm{RMS})}=410 \mathrm{~mA}$. The temperature distribution within the diode package is the same 
as for the previous situation, while the maximum reached temperature value is $152{ }^{\circ} \mathrm{C}$ in the case of measurement (Figure 14a). Simulation analysis was performed at given conditions according to the second measurement, and results are seen in Figure $14 \mathrm{~b}$. The hot spot, in this case, reached $153.43{ }^{\circ} \mathrm{C}$, thus representing a relative error during this situation on the level of $0.94 \%$.

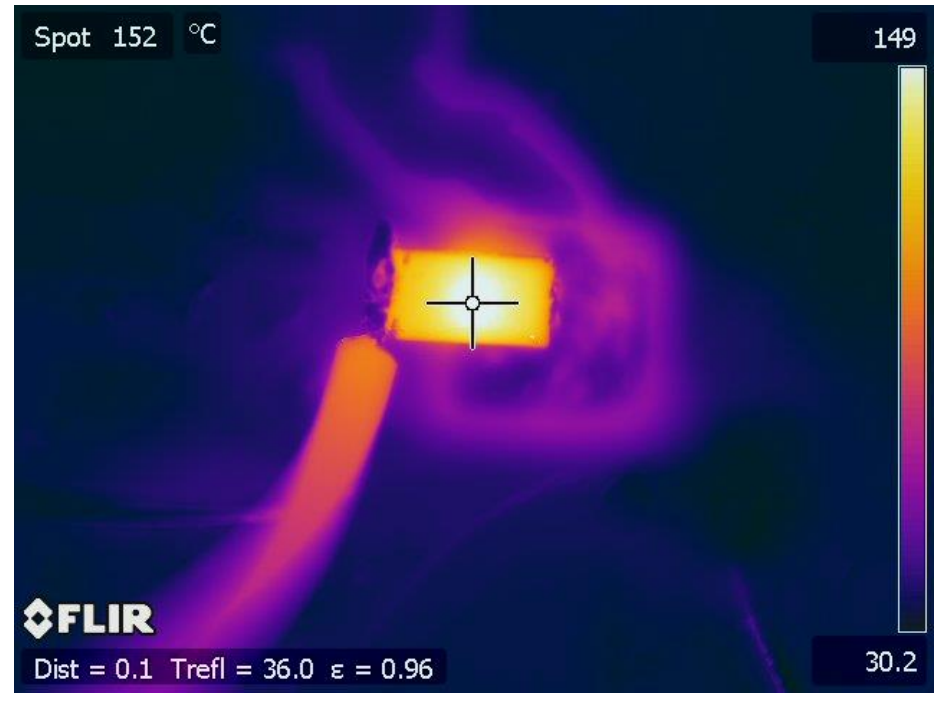

(a)

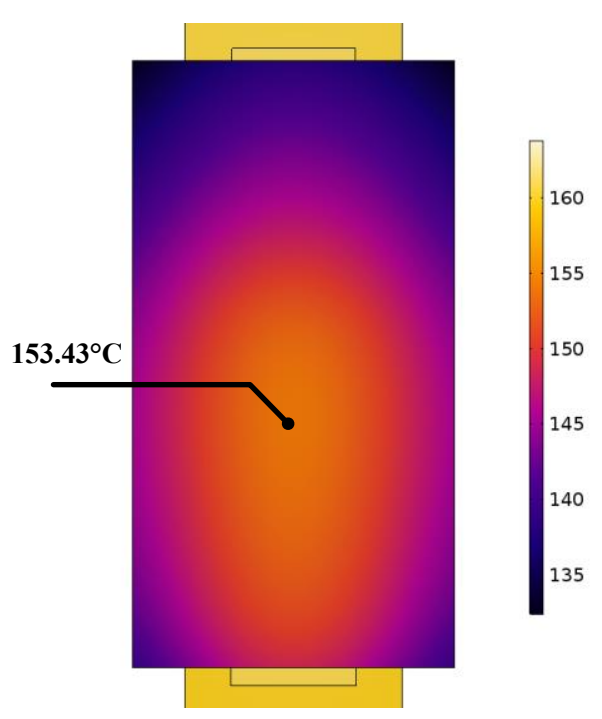

(b)

Figure 14. The Comparison for 410 (mA) forward current: (a) measurement; (b) simulation result.

Because the operational maximum of selected power diode, from the thermal performance point of view, is defined as $150{ }^{\circ} \mathrm{C}$, the last experiment was realized for $500 \mathrm{~mA}$. The temperature maximum is defined for the body of the diode; therefore, even though the temperature reached $152{ }^{\circ} \mathrm{C}$ within the previous experiment, it must be noted here that the device temperature, considering the whole volume, is around $100{ }^{\circ} \mathrm{C}$.

Figure 15a shows thermal distribution during measurement for $\mathrm{I}_{\mathrm{F}(\mathrm{RMS})}=500 \mathrm{~mA}$. The temperature hot spot reached over $192{ }^{\circ} \mathrm{C}$ and this point represents the maximum operational limit considering the temperature of the device. Consequently, a simulation experiment was performed for the last value of forward current. The results are shown in Figure $15 b$, while it is seen that the hot spot reached a maximum temperature at the value of $183.67^{\circ} \mathrm{C}$. This last comparison represents the highest relative error $(-4.3 \%)$ from individual experiments. This is closely related to the $\mathrm{V}-\mathrm{A}$ characteristic at $150{ }^{\circ} \mathrm{C}$ shown in Figure 12, where it is seen that the shape of the characteristic between measurement and simulation represents the highest deviation. 


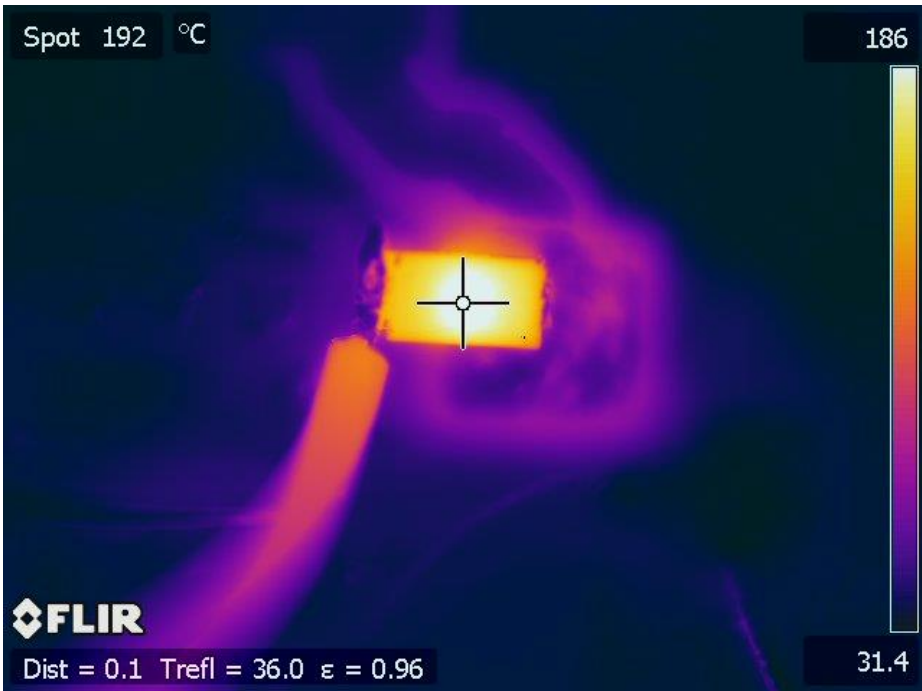

(a)

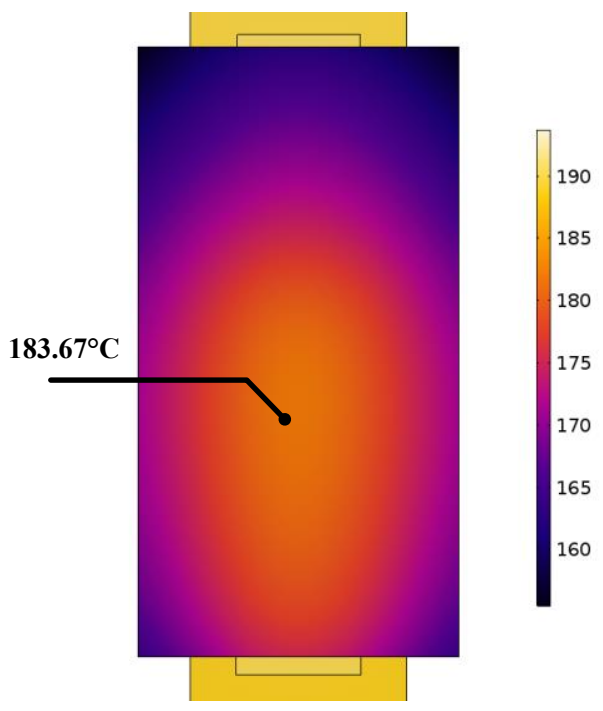

(b)

Figure 15. The Comparison for 500 (mA) forward current: (a) measurement; (b) simulation result.

\section{Conclusions}

The paper presents a modelling approach based on the indirect identification of key variables required for electro-thermal simulation of semiconductor devices. The design procedure of the semiconductor diode is discussed here. Initially, the geometrical model within the CFD software (COMSOL) was realized based on the $X$-ray frames received by the manufacturer. The definitions of the geometrical parameters given within the paper show how it is possible to prepare a fully reconfigurable simulation model. Individual parameters of the geometrical part are then related to the physical properties of the model. After this, the identification of the parameters, which influence the temperature performance of the component, was provided, i.e., physical variables like conductivities of individual component's subdomains were identified. The procedure of the parameter identifications is indirect, i.e., the designer does not need to receive material properties defined by the manufacturer [14]. The proposed methodology uses identification based on V-A diode characteristics. The validation of the proposed model accuracy and validity was evaluated by the results received from the experimental measurement. The evaluation was based on an investigation of temperature distribution within the component surface for various operational conditions considering different power loading of the component. After evaluation, it was found that the relative error between results from simulation and measurements varies from $0.94 \%$ to $-4.3 \%$. This difference is dependent on the amount of the forward current flowing through the diode. Increased error reported at the end of the paper were caused by the unspecified structural component changes at higher temperatures. Generally, it can be concluded that the presented approach represents a perspective way of electrothermal modeling of semiconductor components, thus eliminating the need for the use of semiconductor physics during the development of simulation models. Moreover, it enables the improvement of computation time, maintaining adequate accuracy and performance of simulation model.

Finally, it is important to note that existing methods for thermal field identification require mostly estimation of power dissipation within the given component. In other words, a designer needs to calculate power losses for each of the operational conditions to receive results of thermal performance for a wide operational range (transient or steady state). The presented method, does not require recalculations of the power dissipation, because the model uses electro-thermal domain, and automated-indirect extraction of required variables to identify thermal field distribution. Based on the presented approach more flexibility related to the automated calculation process should be obtained. Moreover, the 
presented modelling approach enables the analysis of electronic components in transient as well as in steady-state operations dynamically, without the need to look-up the table of power dissipation required for various conditions.

Author Contributions: Conceptualization, methodology, writing-original draft preparation, and funding acquisition, M.F., software, validation, and investigation M.P. All authors have read and agreed to the published version of the manuscript.

Funding: This research was funded by National Grant Agency Vega, grant number 1/0063/21 and by National Grant Agency APVV for project funding APVV-17-0218.

Institutional Review Board Statement: Not applicable.

Informed Consent Statement: Not applicable.

Data Availability Statement: Not applicable.

Acknowledgments: The authors wish to thank for the support to the Slovak grant agency Vega for project no. 1/0063/21.

Conflicts of Interest: The authors declare no conflict of interest.

\section{References}

1. Vakrilov, N.; Stoyanva, A.; Bonev, B. 3D Thermal Modelling and Verification of Power Electronic Modules. In Proceedings of the 42nd International Spring Seminar on Electronics Technology (ISSE), Wroclaw, Poland, 15-19 May 2019; pp. 1-4. [CrossRef]

2. Frivaldsky, M.; Spanik, P.; Drgona, P.; Loncova, Z. Algorithms for indirect investigation of heat distribution in electronic systems. Int. J. Therm. Sci. 2016, 114, 15-34. [CrossRef]

3. Valdovinos, M.S. Energy and concentration nonequilibrium and nonlinear charge transport phenomena in semiconductors in a magnetic field in hot electrons approximation. Int. J. Therm. Sci. 2018, 137, 110-120. [CrossRef]

4. Spanik, P.; Cuntala, J.; Frivaldsky, M.; Drgona, P. Investigation of Heat Transfer of Electronic System through Utilization of Novel Computation Algorithms. Elektron. Ir Elektrotechnika 2012, 123, 31-36. [CrossRef]

5. Rafajdus, P.; Peniak, A.; Dubravka, P. Optimization of Switched Reluctance Motor Design Procedure for Electrical Vehicles. In Proceedings of the International Conference on Optimization of Electrical and Electronic Equipment (OPTIM), Bran, Romania, 22-24 May 2014; pp. 1-4. [CrossRef]

6. Wang, Z.; Tian, X.; Liang, J.; Zhu, J.; Tang, D.; Xu, K. Prediction and measurement of thermal transport across interfaces between semiconductor and adjacent layers. Int. J. Therm. Sci. 2014, 79, 266-275. [CrossRef]

7. Eveloy, V.; Lohan, J.; Rodgers, P. A Benchmark Study of Computational Fluid Dynamics Predictive Accuracy for ComponentPrinted Circuit Board Heat Transfer. IEEE Trans. Compon. Packag. Technol. 2000, 23, 568-576. [CrossRef]

8. Ammous, A.; Sellami, F.; Ammous, K.; Morel, H.; Allard, B.; Chante, J.P. Developing an equivalent thermal model for discrete semiconductor packages. Int. J. Therm. Sci. 2003, 23, 266-275. [CrossRef]

9. Tatchell, D.; Parry, J.; Clark, I. Advances in Cooling Electronics with CFD. In Proceedings of the NAFEMS World Congress, Salzburg, Austria, 10-12 June 2013.

10. Koniar, D.; Hargas, L.; Stofan, S. High Speed Video System for Tissue Measurement Based on PWM Regulated Dimming and Virtual Instrumentation. Elektron. Ir Elektrotechnika 2010, 10, 169-172.

11. Ayadi, M.; Fakfakh, M.A.; Ghariani, M.; Neji, R. Developing an equivalent thermal model for discrete DIODE packages. Int. J. Therm. Sci. 2011, 50, 1484-1491. [CrossRef]

12. Andonova, A.; Kim, N.; Vakrilov, N. Estimation the amount of heat generated by LEDs under different operating conditions. Elektron. Ir Elektrotechnika 2016, 22, 49-53. [CrossRef]

13. Mashayekhi, R.; Khodabandeh, E.; Akbari, O.A.; Toghraie, D.; Bahiraei, M.; Gholami, M. CFD analysis of thermal and hydrodynamic characteristics of hybrid nanofluid in a new designed sinusoidal double-layered microchannel heat sink. J. Therm. Anal. Calorim. 2018, 134, 2305-2315. [CrossRef]

14. Hruska, K.; Kindl, V.; Pechanek, R. Design and FEM analyses of an electrically excited automotive synchronous motor. In Proceedings of the 15th International Power Electronics and Motion Control Conference (EPE/PEMC), Novi Sad, Serbia, 4-6 September 2012; pp. LS2e.2-1-LS2e.2-7. [CrossRef]

15. Kucera, M.; Sebok, M.; Kubis, M.; Korenciak, D.; Gutten, M. Analysis of the Automotive Ignition System for Various Conditions. Commun.-Sci. Lett. Univ. Zilina 2020, 22, 144-152. [CrossRef]

16. Staliulionis, Z.; Zhang, Z.; Pittini, R.; Andersen, M.A.E.; Noreika, A.; Tarvydas, P. Thermal Modelling and Design of On-board DC-DC Power Converter using Finite Element Method. Elektron. Ir Elektrotechnika 2014, 20, 38-44. [CrossRef]

17. Nobile, G.; Cacciato, M.; Scarcella, G.; Scelba, G. Multi-Criteria Experimental Comparison of Batteries Circuital Models for Automotive Applications. Commun.-Sci. Lett. Univ. Zilina 2018, 20, 97-104. 
18. Kascak, S.; Prazenica, M.; Jarabicova, M.; Paskala, M. Interleaved DC/DC Boost Converter with Coupled Inductors. Adv. Electr. Electron. Eng. 2018, 16, 147-154. [CrossRef]

19. Frivaldsky, M.; Donic, T.; Vavrus, V.; Pavelek, M. Experimental research of optimization methodology for local, resistive-heating of thin molybdenum plates. Int. J. Therm. Sci. 2017, 121, 111-123. [CrossRef]

20. Hockicko, P.; Bury, P.; Munoz, F. Investigation of relaxation and transport processes in LIPO(N) glasses. J. Non-Cryst. Solids 2013, 363, 140-146. [CrossRef]

21. Kascak, S.; Resutik, P. Method for estimation of power losses and thermal distribution in power converters. Electr. Eng. 2021, 1-12. [CrossRef]

22. Zavrel, M.; Kindl, V.; Kavalír, T.; Drabek, P. Design and Construction of High-Quality Capacitor for High Frequency and Power Application. Commun.-Sci. Lett. Univ. Zilina 2018, 23, C1-C6. [CrossRef]

23. Hockicko, P.; Kudelcik, J.; Munoz, F.; Munoz-Senovilla, L. Structural and electrical properties of LIPO3 Glasses. Adv. Electr. Electron. Eng. 2015, 13, 198-205. [CrossRef]

24. US1MHE3-61T Datasheet-Vishaz Siliconix. Available online: vhttps://www.googleadservices.com/pagead/aclk?sa=L\& ai=DChcSEwjS7cTdrfz0AhWButUKHaqMAygYABAAGgJ3cw\&ae=2\&ohost=www.google.com\&cid=CAASEuRooSqOxyr_e6 iByfNUFAkFuw\&sig=AOD64_04IojJYKQHeBYAxSozhWlT2q4cyA\&q\&adurl\&ved=2ahUKEwiN0brdrfz0AhVpSfEDHYYBA6 0Q0Qx6BAgCEAE (accessed on 15 May 2021). 